\title{
Individual Book Reports: An Application of Differentiated Instruction in Two Public Health College Courses
}

\author{
Parley Cougar Hall* ${ }^{\circledR}$, Christopher B. Curtis, Joshua H. West \\ Department of Public Health, Brigham Young University, Provo, Utah, USA \\ Email: *coughall@gmail.com
}

How to cite this paper: Hall, P.C., Curtis, C.B. and West, J.H. (2019) Individual Book Reports: An Application of Differentiated Instruction in Two Public Health College Coursese. Health, 11, 1247-1256. https://doi.org/10.4236/health.2019.1110096

Received: August 31, 2019

Accepted: October 6, 2019

Published: October 9, 2019

Copyright $\odot 2019$ by author(s) and Scientific Research Publishing Inc. This work is licensed under the Creative Commons Attribution International License (CC BY 4.0).

http://creativecommons.org/licenses/by/4.0/

\section{(c) (i) Open Access}

\begin{abstract}
As an anecdote to the one-size-fits-all curriculum, differentiation presents a pedagogical opportunity to accommodate learner variance. Differentiated instruction typically aims to address variance in at least one of the following areas: 1) student readiness; 2) student learning profiles; and 3) student interests. While each aim is fundamentally important to effectively differentiating instruction, the purpose of this descriptive best practice paper was to present a simple approach for addressing variance in individual student interest in a university setting. Participants in this teaching activity included 175 students enrolled in one of two undergraduate-level courses in the Department of Public Health at a large private university in the United States. Each participant was asked to select a book related to his or her chosen career path and that aligned with a topic covered in the course. Students selected the book of their choice and submitted the title to the principle investigator who reviewed each selection. Students were given approximately six weeks to read their selected books and write a brief book report. Participants completed a brief online survey assessing the value of this teaching approach. Descriptive analyses indicate this teaching activity was widely considered to be meaningful and beneficial, supporting the inclusion of differentiated instructional approaches at the university level.
\end{abstract}

\section{Keywords}

Differentiated Instruction, Public Health, College, University

\section{Introduction}

Differentiated instruction or differentiated teaching is a framework for effective teaching that involves providing students within the same course with different 
avenues to learning. This instructional approach is rooted in the belief that students learn best when instructors accommodate the differences in their readiness levels, interests and learning profiles [1]. One way of viewing differentiation is to regard it as an approach that encourages instructors to respond to differences among individuals, while maintaining high-performance expectations for all students. In response to a wide range of individual student interests, ability, rates of learning, learning styles, and prior knowledge, differentiated instruction may be considered targeted instruction delivered in a whole-group setting. Differentiated instructional approaches are typically implemented to personalize instruction for various student backgrounds, readiness levels, languages, interests and learning profiles [2] [3]. As classrooms have become increasingly diverse, the need for this instructional approach has intensified [4].

Differentiated approaches have most commonly been applied in K-12 settings where a wide range of ability and background knowledge tend to exist. However, applying a differentiated instructional approach has also been shown to be efficacious in college courses. In a study conducted by Chamberlin and Powers [5], undergraduate elementary education majors in mathematics classes were found to benefit from differentiated instruction. Ernst and Ernst examined a differentiated approach with students in their undergraduate political science classes [6]. Students were assessed and assigned into one of three groups based upon their readiness level and background experience for addressing public policy issues. Based upon these group allocations, the researchers provided several possible assignments aligned with student's personal interests and perceived strengths. Next, students were paired into a second group based upon political identification (conservative or liberal) where they worked collaboratively in differing roles to prepare for a political debate related to public policy issues. The authors reported strong student participation, especially as students were engaged in specific tasks aligned with their personal interests and perceived competencies. The result was a vast improvement over previous approaches where all students were required to complete the same tasks regardless of individual student differences [6]. A study conducted by Santangelo and Tomlinson [7], took a similar approach in an introductory education and psychology class for graduate students. Following a pre-assessment to determine student interest and readiness for the course, students were provided additional resources to supplement individual learners. For example, students arriving with a very basic understanding of subject matter were provided with materials designed to give a general overview of the course content while targeting key points and necessary background knowledge. Students already possessing this background knowledge, however, were provided more advanced discussion topics, readings, and assignments aligned with their existing knowledge. In addition to providing a broad selection of complementary learning resources, the course assignments were also differentiated in allowing students autonomy in how they met project learning objectives [7]. 
The greatest challenge in implementing differentiated approaches similar to those taken by Ernst and Ernst [6] or Santangelo and Tomlinson [7] in a college or university setting is likely the time and resources required. Modifying lesson plans or units of study to accommodate diversity among learners may seem simple in theory, but when faced with specific instructional decisions and applications, many instructors may feel lost or overwhelmed. For instructors to implement differentiated teaching effectively, the strategies they use must be manageable and sustainable over time. Too often elaborate attempts to differentiate instruction end in confusion for students and frustration for instructors. To sustain a differentiated approach, adaptations to curriculum and teaching methods are most effective when they are modest, easy to design and implement, and are based on assignments and activities that may typically be included in the curriculum. The purpose of this descriptive best practice paper was to examine a simple and sustainable approach to differentiated instruction addressing variance in individual student interest in two public health courses in a university setting.

\section{Methods}

This descriptive paper aims to highlight a pedagogical approach consistent with differentiated instruction and is not presented here as an original research piece. However, to help explore the efficacy of this approach Institutional Review Board approval was obtained and primary data are presented.

Participants. Participants in this teaching activity included 175 students enrolled in one of two undergraduate-level courses in the Department of Public Health at a large private university in the United States. The majority of participants were enrolled in a Mind-Body Health course during the 2017-18 academic year, either Fall Semester, Winter Semester, or Spring Term. A semester-long, 3-credit hour course, Mind/Body Health explores emerging research and application from the field of psychoneuroimmunology. A smaller number of student participants were enrolled in a Sexuality Education course during the 2017 Fall Semester. This course was designed to meet the needs of pre-service community health educators, school health educators, and family life educators. These courses were selected because of their broad appeal and the subsequent variety of academic majors enrolled. While these courses are required or elective offerings for many students in the Department of Public Health, they also attract students from a variety of other disciplines and programs across the university. For example, during the semester prior to this study, 25 different academic majors were represented in just these two courses making them a strong selection for study participation.

Procedure. Each participant was asked to select a book related to his or her chosen career path and that aligned with a topic covered in the course. Students selected the book of their choice and submitted the title to the principle investigator who reviewed each selection and ordered the books from an online retail- 
er. Students were given approximately six weeks to read their selected books and write a brief book report. Reports were assessed using a scoring guide including the following: 1) book reference in APA format; 2) author information; 3) student opinion of the book; and 4) outline of the book's big ideas or main points. At the end of each semester, participants were invited to report their opinion of this learning activity by completing a brief online survey. Completion of the survey was incentivized by offering 10 extra credit points.

Instrument. The first item of the survey was the consent to participate. If students did not consent to participation, then the survey ended with a message stating that 10 points of extra credit could alternatively be earned by finding and submitting a research article addressing a topic discussed in the course. Consenting students were able to proceed with the survey which included the following items: 1) What year in school are you? (Freshman, Sophomore, Junior, Senior, Other); 2) What is your sex? (Female, Male); 3) Completing this course... (Fulfills a program of study requirement; Fulfills a program of study elective requirement; Fulfills a graduation elective requirement; None of the above); 4) What is your major of study? (open-ended); 5) What is your anticipated profession? (open-ended); 6) In this course you were asked to select a book covering a topic which aligns with your anticipated profession and at least one topic presented in the class. You were asked to read your selected book and write a brief book report summarizing the main points presented in the book. The following questions refer specifically to this learning activity and are answered using a Likert scale including the options "strongly agree, somewhat agree, neither agree or disagree, somewhat disagree, strongly disagree": 1) I found this learning activity to be worthwhile; 2) I found this learning activity to be enjoyable; 3) I believe this learning activity has aided my professional/career preparation; 4) I believe this learning activity aided my personal application of topics presented in the course; 5) This learning activity was responsive to my personal education needs; 6) This learning activity increased my knowledge of course concepts/content; 7) This learning activity allowed me to personalize my learning experience.

Analysis. Data collected and analyzed were entirely descriptive and no hypothesis was established. For these reasons, analyses beyond simple descriptive statistics were not performed.

\section{Results}

The majority of participants in this study $(\mathrm{N}=175)$ were female $(86.86 \%)$, which is higher than the average in the department as a whole (59.91\%). More Juniors (30.29\%) and Seniors (44.43\%) participated than Sophomores (9.71\%) and Freshman (4.0\%). Demographics, including academic majors, reasons for taking the course, and intended career paths are displayed in Table 1. Students in Mind-Body Health and Sexuality Education, two courses offered within the Department of Public Health, participating in this study came from 15 different majors across campus. The majority of participants $(76.57 \%)$ anticipated taking one of six different career paths. 
Table 1. Sample characteristics.

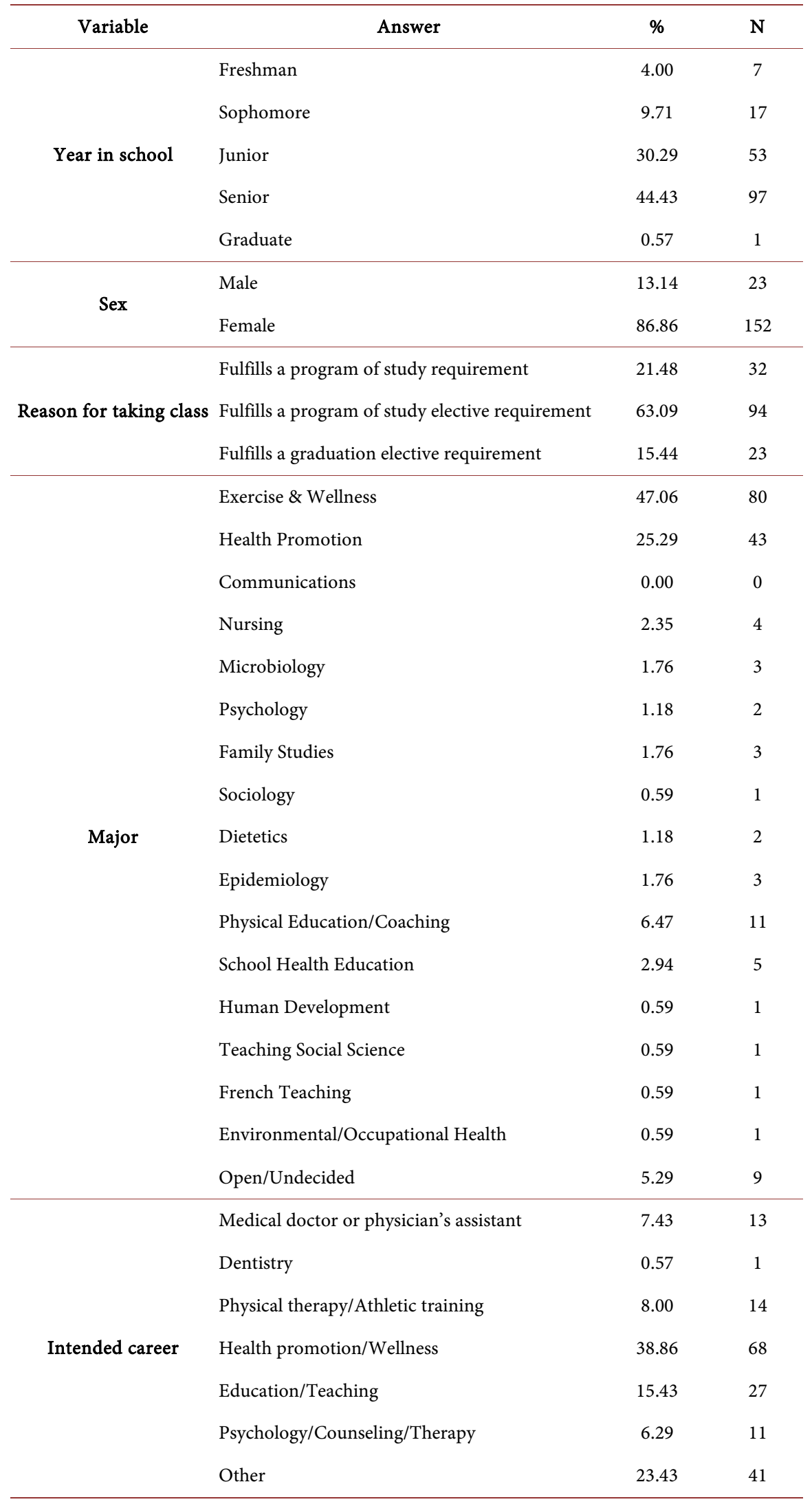


Table 2 includes participants' attitudes toward the learning activity. A majority of participants found the learning activity to be worthwhile (93.71\% strongly agreeing or agreeing) and enjoyable (96.14\% strongly agreeing or agreeing). Results were similar among participants' beliefs that the learning activity aided their professional/career preparation (89.15\% strongly agreeing or agreeing) and their personal application of course topics (92.53\% strongly agreeing or agreeing). Participants' reported that this learning activity was responsive to their personal education needs (90.28\% strongly agreeing or agreeing), increased their knowledge of course concepts (88.57\% strongly agreeing or agreeing), and allowed for personalization of the learning experience (95.43\% strongly agreeing or agreeing).

\section{Discussion}

While not designed as a research study, this article provides support for teaching activities designed to provide differentiated instruction to students in college courses. Participants came from a wide variety of majors and professional interests and yet nearly all responses can be considered favorable or supportive of this learning activity. Participants in this study found this approach to be responsive to their personal needs and beneficial to their professional preparation. Moreover, participants considered the approach to be both enjoyable and worthwhile. In so much as individual student interests and professional aspirations provide purpose and motivation for learning, university instructors should attempt to leverage these forces through the inclusion of differentiated approaches [8].

Even the modest differentiated instructional approach evaluated in this study resulted in approximately $90 \%$ of students indicating relevance to their professional career preparation and high levels of perceived worthwhileness, and enjoyment.

Table 2. Attitudes toward the learning activity.

\begin{tabular}{|c|c|c|c|c|c|c|c|c|c|c|c|}
\hline Question & $\begin{array}{l}\text { Strongly } \\
\text { agree }\end{array}$ & $\mathbf{N}$ & $\begin{array}{l}\text { Somewhat } \\
\text { agree }\end{array}$ & $\mathbf{N}$ & $\begin{array}{l}\text { Neither agree } \\
\text { nor disagree }\end{array}$ & $\mathbf{N}$ & $\begin{array}{l}\text { Somewhat } \\
\text { disagree }\end{array}$ & $\mathbf{N}$ & $\begin{array}{l}\text { Strongly } \\
\text { disagree }\end{array}$ & $\mathbf{N}$ & Total \\
\hline I found this learning activity to be worthwhile. & $76.00 \%$ & 133 & $17.71 \%$ & 31 & $1.71 \%$ & 3 & $1.71 \%$ & 3 & $2.86 \%$ & 5 & 175 \\
\hline I found this learning activity to be enjoyable. & $76.00 \%$ & 133 & $17.14 \%$ & 30 & $1.14 \%$ & 2 & $4.00 \%$ & 7 & $1.71 \%$ & 3 & 175 \\
\hline $\begin{array}{l}\text { I believe this learning activity has aided my } \\
\text { professional/career preparation. }\end{array}$ & $58.86 \%$ & 103 & $30.29 \%$ & 53 & $5.14 \%$ & 9 & $3.43 \%$ & 6 & $2.29 \%$ & 4 & 175 \\
\hline $\begin{array}{l}\text { I believe this learning activity aided my } \\
\text { personal application of topics presented in } \\
\text { the course. }\end{array}$ & $67.82 \%$ & 118 & $24.71 \%$ & 43 & $2.87 \%$ & 5 & $1.72 \%$ & 3 & $2.87 \%$ & 5 & 174 \\
\hline $\begin{array}{l}\text { This learning activity was responsive to my } \\
\text { personal education needs. }\end{array}$ & $72.57 \%$ & 127 & $17.71 \%$ & 31 & $4.57 \%$ & 8 & $2.29 \%$ & 4 & $2.86 \%$ & 5 & 175 \\
\hline $\begin{array}{l}\text { This learning activity increased my } \\
\text { knowledge of course concepts/content. }\end{array}$ & $62.86 \%$ & 110 & $25.71 \%$ & 45 & $6.29 \%$ & 11 & $2.86 \%$ & 5 & $2.29 \%$ & 4 & 175 \\
\hline $\begin{array}{l}\text { This learning activity allowed me to } \\
\text { personalize my learning experience. }\end{array}$ & $85.14 \%$ & 149 & $10.29 \%$ & 18 & $1.14 \%$ & 2 & $0.57 \%$ & 1 & $2.86 \%$ & 5 & 175 \\
\hline
\end{tabular}


A perceived disconnect between what is being taught and how it will help students in their future profession presents a significant challenge in garnering individual student interest. It is not uncommon for students to consider the content and learning activities of their courses to be unrelated to their professional interests or goals, resulting in beliefs and attitudes that they are wasting their time, effort, and money [9] [10]. Students need to see utility, or goal relevance, in some aspect of what they are learning, or interest will wane, and their learning may be limited [11]. In a study by Gorham and Millette [10], perceived relevance and interest in the subject matter were ranked first by both college students and their instructors among factors influencing motivation to learn.

Nearly all student participants indicated that this teaching approach allowed them to personalize the learning experience. The differentiated instructional approach evaluated herein was merely one assignment among many in these college courses and may not adequately address or represent efforts to personalize instruction. However, even this modest effort at personalization was appreciated by students in this study. Waldeck [12] notes that students' perceptions of personalization in the classroom increase when students feel autonomous in selecting projects that are of interest to them. There is a strong need, however, to ensure an association between the activities students select and the learning outcomes of the course. Assigning individual book readings and reports that align with, or intersect where, course content and professional interests come together, can provide for personalization while still meeting course learning outcomes [12]. In the case of this proposed instructional activity, personalization and enjoyment were high while students also reported increases in knowledge of course content and concepts, an indication of proper alignment with course learning outcomes.

Although differentiated instruction at the K-12 level has received much attention and is of great benefit, application at the university level provides opportunities to address several potential challenges frequently encountered in higher ed. Both required and elective university courses where many students are pursuing different professional aims present a great opportunity to apply differentiated instruction. While university students represent an assortment of learning abilities, aptitudes, and backgrounds, it may be that varied professional interests and career motivations present the greatest degree of variance between students. As student interests and engagement in university courses vary, these interests can become effective tools to support learning and increase engagement. The instructional strategy presented herein allows for all students to pursue learning directly aligned with particular career interests. Large class sizes present similar challenges for tailoring learning to individual student needs. This instructional activity has great utility in that it can be implemented in university classes of various sizes.

While this paper presents only brief descriptive results in support of differentiated instruction at the university level, these results are largely consistent with 
other findings. In studies performed by both Ernst and Ernst [6] and Santangelo and Tomlinson [7], students reported high satisfaction from differentiated instruction. In the study by Ernst and Ernst [6], an overwhelming majority of the students who participated stated they felt challenged and were able to live up to their academic ability. The authors reported that only $7 \%$ of students would have preferred greater use of the traditional lecture format [6]. Santangelo and Tomlinson [7] found that $100 \%$ of students participating in the study had mastered all course learning objectives, and $56 \%$ of students had exceeded course learning objective expectations. While neither study indicated that differentiated instruction improved students' grades compared to other standard lecture-based instruction, both studies showed that students felt that they could study and learn based on their personal interests leading to more satisfying learning experiences in the classroom [6] [7].

Adaptations: This instructional approach should be adapted to meet specific course objectives and learning outcomes. Furthermore, specific procedures can be tailored to improve instructional outcomes. For example, while this teaching idea was supported by a small internal grant at the study university, adaptations could include requiring students to purchase the book of their choice or encouraging them to find a suitable book at the library. Instructors may choose to develop and maintain a registry of suitable books which both align well with various professional interests and course content to help guide students in their book selection. Such a list may also include a review or comments from previous students and would serve to help students select a suitable book. Another adaptation for improvement includes grouping students with similar professional interests into book clubs where they can share and discuss key points from their individual books, how ideas from their books relate to course content, and professional insights gained from their reading throughout the semester. Finally, where available, students could share insights from their reading in an online class forum or digital dialogue. Instructors could post a weekly topic related to the course and ask students to share associated insights gleaned from their individual reading. This approach may encourage higher order thinking and foster additional opportunities to deepen understanding of course content. Instructors should seek student feedback and feel free to explore ideas for improvement of this differentiated approach.

This descriptive paper sought to highlight and briefly evaluate a pedagogical approach consistent with differentiated instruction but is not specifically intended as a research paper. Given this aim, there are several key limitations that should be mentioned. First, full participant demographic information was not collected. The study survey did not include information concerning age, race or ethnicity, socioeconomic status, marital status, or prior academic success. Second, there was no control group or alternate intervention with which to compare results. Finally, the study's sample size was limited and not well distributed by sex which limited certain statistical measures. 


\section{Conclusion}

While recognizing that many learning needs and objectives are common to all students, differentiated instruction has the ability to address at least some specific needs of individual learners. The primary value of this proposed teaching innovation is that it offers differentiated instruction for a large group of students with diverse professional interests.

\section{Funding Sources}

This project was funding through a Teaching Enhancement Grant from the College of Life Science at Brigham Young University, Provo, Utah, USA.

\section{Conflicts of Interest}

The authors declare no conflicts of interest regarding the publication of this paper.

\section{References}

[1] Tomlinson, C. (2005) Grading and Differentiation: Paradox or Good Practice? Theory into Practice, 44, 262-269. https://doi.org/10.1207/s15430421tip4403_11

[2] Hall, T., Strangman, N. and Meyer, A. (2002) Differentiated Instruction and Implications for UDL Implementation. http://www.cast.org/udlcourse/DifferInstruct.doc

[3] Tomlinson, C., Brighton, C., Hertberg, H., Callahan, C., Moon, T., Brimijoin, K., Reynolds, T., et al. (2003) Differentiating Instruction in Response to Student Readiness, Interest, and Learning Profile in Academically Diverse Classrooms: A Review of the Literature. Journal for the Education of the Gifted, 27, 119-145. https://doi.org/10.1177/016235320302700203

[4] Mulroy, H. and Eddinger, K. (2003) Differentiation and Literacy. The Institute on Inclusive Education, Rochester.

[5] Chamberlin, M. and Powers, R. (2010) The Promise of Differentiated Instruction for Enhancing the Mathematical Understandings of College Students. Teaching Mathematics and Its Applications, 29, 113-139.

https://doi.org/10.1093/teamat/hrq006

[6] Ernst, H.R. and Ernst, T.L. (2005) The Promise and Pitfalls of Differentiated Instruction for Undergraduate Political Science Courses: Student and Instructor Impressions of an Unconventional Teaching Strategy. Journal of Political Science Education, 1, 39-59. https://doi.org/10.1080/15512160590907513

[7] Santangelo, T. and Tomlinson, C. (2009) The Application of Differentiated Instruction in Postsecondary Environments: Benefits, Challenges, and Future Directions. International Journal of Teaching and Learning in Higher Education, 20, 307-323.

[8] Tomlinson, C. (2001) How to Differentiate Instruction in Mixed-Ability Classrooms. 2nd Edition, Association of Supervision and Curriculum Development, Alexandria.

[9] Bergin, D. (1999) Influences on Classroom Interest. Educational Psychologist, 34, 87-98. https://doi.org/10.1207/s15326985ep3402_2

[10] Gorham, J. and Millette, D. (1997) A Comparative Analysis of Teacher and Student Perceptions of Sources of Motivation and Demotivation in College Classes. Communication Education, 46, 245-261. https://doi.org/10.1080/03634529709379099 
[11] Frymier, A. and Shulman, G. (1995) "What's in It for Me?": Increasing Content Relevance to Enhance Students' Motivation. Communication Education, 44, 40-50. https://doi.org/10.1080/03634529509378996

[12] Waldeck, J. (2007) Answering the Question: Student Perceptions of Personalized Education and the Construct's Relationship to Learning Outcomes. Communication Education, 56, 409-432. https://doi.org/10.1080/03634520701400090 